know that many potential library users manage very well without such help.

Librarians and information scientists can be trained to cope with the technicalities of retrieving and transferring information from the present commercially available data bases as well as from those generated by research workers, academics, students, and administrators. Conceivably, however, the automated information explosion will be so vast that a specially trained intermediary will have to evaluate the results of the search, not the person who has initiated the query.

Automation has a very important part to play in the library of the future, but it must not be thought that economies will automatically follow. The cost of terminals, the use of data bases, and the training of staff in different techniques will need capital funds as well as a continuing financial commitment. Nevertheless, the availability of more information and its use for the benefit of students, research workers, clinicians, and, ultimately, the patient will eventually justify the cost.

G M Pentelow

Librarian,

King's College Hospital Medical School, London SE5 8RX

1 Matheson NW, Cooper JAD. Academic information in the Academic Health Sciences Center; roles for the library in information management. f Med Educ 1982;57, 10, part 2:1-93.

\section{Digitalis intoxication: a new approach to an old problem}

Since the use of the foxglove was first described by Withering almost 200 years ago several digitalis glycosides have been isolated and purified. Of these, two (digoxin and digitoxin) are in common use. They share several properties, including a positive inotropic effect and an action to delay atrioventricular conduction, most of which is mediated by the vagus nerves. In addition, both drugs have a narrow therapeutic indexthat is, the dose that produces toxicity lies close to that which produces clinical benefit. They vary, however, in their chemical structure, a feature that leads to differences in their pharmacokinetics: digoxin is excreted mainly unchanged in the urine, whereas digitoxin undergoes metabolism in the liver, excretion in the bile, and enterohepatic recirculation. Digitalis intoxication may occur whenever the excretory pathways are compromised or an inappropriately large dose of drug is given, or both. Because the glycoside in most common use in Britain is digoxin, the feature that predisposes to intoxication is renal failure, usually consequent on old age. ${ }^{1}$ Occasionally, however, digitalis glycosides are taken in deliberate overdose, and rarely an error in the dose given is made by either medical or nursing staff.

The response to digitalis glycosides varies with many factors, including the type and duration of the heart disease, accompanying anoxia, and the concentrations of sodium, potassium, calcium, and magnesium in the tissues and blood. ${ }^{2}$ The glycosides inhibit the action of the membrane bound enzyme sodium/potassium ATPase, ${ }^{3}$ and similar effects occur with hypokalaemia. Hence the latter is an important contributory factor in digitalis intoxication, being particularly likely to occur in patients who are receiving either a benzothiadiazine or a loop type diuretic ${ }^{4}$ such as frusemide or bumetanide (which also causes magnesium depletion). Hypothyroidism is another predisposing factor for digitalis intoxication, partly because glomerular filtration is depressed. ${ }^{5}$ In addition, the activity of the sympathetic nervous system may determine whether or not a patient develops a cardiac arrhythmia. Besides diuretics, many other drugs may interact to increase the risks of digitalis intoxication. ${ }^{6}$ Notable among these are other cardioactive drugs, particularly antiarrhythmic agents. $^{7}$

Whatever its underlying aetiology, digitalis intoxication is common. Of the various estimates of its prevalence, the highest is from the United States, where almost a third of patients receiving cardiac glycosides when admitted to hospitals in Boston were definitely or possibly intoxicated. ${ }^{8}$ In Britain, a study from Belfast showed that about a fifth of patients receiving digitalis glycosides developed adverse effects. ${ }^{4}$ In contrast, of 391 patients attending general practices in Liverpool, only 37 had serum concentrations exceeding the "therapeutic range."9 Nevertheless, intoxication may occur at serum concentrations within the "therapeutic range," especially if the plasma potassium concentration falls below normal.

Most of the side effects of digitalis glycosides were recognised by Withering. General symptoms include anorexia, nausea, vomiting, and diarrhoea, but these are non-specific. ${ }^{10}$ The manifestations in the central nervous system include mistiness or yellowed vision, confusion, and a "psychotic" state in the elderly. ${ }^{11}$ Cardiac manifestations of toxicity include worsening of heart failure, but almost any disturbance of rhythm and conduction may occur (with the exception of Mobitz type II atrioventricular block, parasystole, and junctional tachycardia). ${ }^{10}$ The most frequent abnormalities are ventricular extrasystoles (coupling) and either first or second degree atrioventricular block. Complete atrioventricular dissociation may occur, and atrial tachycardia with atrioventricular block (usually $2: 1$ ) is common.

The diagnosis of digitalis toxicity is usually simple. The development of malaise, gastrointestinal upset, or a new arrhythmia in someone who is receiving digitalis glycosides should provoke suspicion. If these features get better after the drug has been withdrawn or its dose reduced then this is further support for the diagnosis. Measurement of the concentration of the glycoside in the plasma or serum, however, together with estimation of the plasma potassium concentration may be very helpful. If the latter is normal toxicity is unlikely with plasma digoxin concentrations below $2.5 \mathrm{nmol} / 1(2 \mathrm{ng} / \mathrm{ml})$, whereas toxicity is very likely with values above $5 \mathrm{nmol} / 1$ $(4 \mathrm{ng} / \mathrm{ml}) .{ }^{12}$ Nevertheless, in patients whose plasma potassium concentrations are below normal plasma glycoside concentrations between 1.3 and $2.5 \mathrm{nmol} / 1$ may be associated with toxicity. Assessment of colour vision with the FarnsworthMunsell test may be helpful in confirming the diagnosis in some patients, ${ }^{13}$ but in my view pharmacological tests such as the administration of acetylstrophanthidin, edrophonium, or edetic acid are not only unreliable but also potentially dangerous.

The principles of treatment of digitalis toxicity are similar to those underlying the management of all drug overdoses. Firstly, the treatment should be stopped-at least temporarily. Secondly, for digitoxin, absorption from the gastrointestinal \title{
.
}

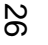


tract should be prevented with either cholestyramine or colestipol, ${ }^{14}$ both of which will also hasten its elimination from the body. Next, restoration of the body stores of potassium is important. If intoxication is mild then correction can be with oral potassium supplements, but if the patient has frequent ventricular ectopic beats more rapid restoration by the intravenous route is preferable, at a rate of $20-40 \mathrm{mmol}(\mathrm{mEq})$ an hour. If the patient has syncopal episodes relating to runs of ventricular ectopic beats an antiarrhythmic will be needed; lignocaine is the safest and most useful since it has little or no depressant effect on conduction through the atrioventricular node. Phenytoin is a worthwhile alternative, ${ }^{15}$ perhaps because it opposes the effects of digitalis on membrane bound sodium/potassium ATPase. Alternatively, beta adrenoceptor antagonists such as practolol may revert many disturbances of rhythm induced by digitalis to normal. ${ }^{16}$ (These drugs tend to delay conduction in the heart, so a temporary pacing wire should be inserted before they are used lest complete heart block should supervene.) Direct current cardioversion should be reserved for ventricular fibrillation since the treatment is hazardous; very low energy impulses should be tried initially. ${ }^{17}$

The most exciting development in the management of digitalis overdosage and intoxication has been the introduction of an antidote-namely, digoxin specific antibodies. These are produced in sheep and isolated by a specific immunoadsorbent method. The whole immunoglobulin has a limited distribution in the body and (although binding digoxin) cannot be excreted by the kidney because of its large molecular weight. Nevertheless, proteolytic digestion with the enzyme papain cleaves the IgG molecule into three fragments: a crystallisable fraction $(\mathrm{Fc})$, which is unwanted, and two Fab fragments, which have a molecular weight of about 50000 and possess specific antigen binding sites. One molecule of Fab binds one molecule of digoxin and the complex may then be excreted by the kidney. Small supplies of the antibody have been made available recently by Burroughs Wellcome and initial experience of its use is very encouraging. In particular, Smith and colleagues ${ }^{18}$ have used the purified Fab fragments intravenously in 26 patients with advanced, life threatening digoxin or digitoxin toxicity. Nineteen of their patients had serum digoxin concentrations greater than $6.3 \mathrm{nmol} / 1(5 \mathrm{ng} / \mathrm{ml})$ at the time of antibody administration; 17 had had ventricular tachycardia and nine had developed episodes of ventricular fibrillation. Previously the mortality of patients who developed digitalis induced ventricular tachycardia was very high. ${ }^{19}$ The results in Smith's series were dramatic: all of the 26 patients showed an initial response and 21 made a full recovery. Of those who died, one did so after recurrence of the arrhythmia and was considered to have received inadequate amounts of the antibody. Of the four others, three had had cardiogenic shock for some hours and the fourth sustained anoxic brain damage.

Despite these impressive results, several problems exist. The most important of these is that at present the supply of antibody is very limited. The antibody is derived from sheep serum and might provoke allergic reactions and hence it is recommended that an initial skin sensitivity test should be carried out; after this a small intravenous test dose of the Fab fragments should be given. Nevertheless, in the series reported from Boston no hypersensitivity reactions occurred, and all who have to treat digitalis toxicity will hope that further supplies will be made available for clinical use.

C F GEORGE

Professor of Clinical Pharmacology,

University of Southampton,

Southampton SO9 3TU

${ }^{1}$ Chamberlain DA, White RJ, Howard MR, Smith TW. Plasma digoxin concentrations in patients with atrial fibrillation. $\mathrm{Br}$ Med $\mathcal{7}$ 1970;iii 429-32.

2 Smith TW. Measurement of serum digitalis glycosides. Clinical implica tions. Circulation $1971 ; \mathbf{4 3}: 179-82$.

${ }^{3}$ Noble D. Mechanism of action of therapeutic levels of cardiac glycosides. Cardiovasc Res 1980;14:495-514.

${ }^{4}$ Hurwitz N, Wade OL. Intensive hospital monitoring of adverse reactions to drugs. Br Med $\mathcal{F} 1969 ;$ i:531-6.

${ }^{5}$ Croxson MS, Ibbertson HK. Serum digoxin in patients with thyroid disease. $\mathrm{Br}$ Med 7 1975;iii :566-8.

${ }^{6}$ Manninen V, Nyberg L. Interactions between cardiac glycosides and other substances in the body. In: Greeff K, ed. Pharmacokinetics and clinical pharmacology of cardiac glycosides. Berlin: Springer-Verlag, 1981. (Handbook of experimental pharmacology. Vol 56. Pt 2. Pp 299-336.)

George CF. Interactions with digoxin-more problems. Br Med f 1982; $284: 291-2$.

${ }^{8}$ Beller GA, Smith TW, Abelmann WH, Haber E, Hood WB. Digitalis intoxication: a prospective clinical study with serum level correlations. A study in three Boston hospitals. N Engl f Med 1971;284:989-97.

${ }^{9}$ Liverpool Therapeutics Group. Use of digitalis in general practice. Br Med F 1978;ii :673-5.

10 Bullock RE, Hall RJC. Digitalis toxicity and poisoning. Adverse Drug Reactions and Acute Poisoning Reviews 1982;1:201-22.

11 Church G, Marriott HJL. Digitalis delirium. A report on three cases. Circulation 1959;20:549-53.

${ }^{12}$ Shapiro $\mathrm{W}$. Correlative studies of serum digitalis levels and the arrhythmias of digitalis intoxication. Am F Cardiol 1978;41 :852-9.

${ }_{13}$ Aronson JK, Ford AR. The use of colour vision measurement in the diagnosis of digoxin toxicity. Q7 Med 1980;49:273-82.

14 Bazzano G, Bazzano GS. Digitalis intoxication. Treatment with a new steroid-binding resin. $\mathcal{F} A M A 1972 ; 220: 828-30$.

15 Aronson JK. Digitalis intoxication. Clin $S_{c i} 1983 ; 64: 253-8$.

${ }^{16} \mathrm{Gibson} \mathrm{D}$, Sowton E. The use of beta-adrenergic receptor blocking drug in dysrhythmias. Prog Cardiovasc Dis 1969;12:16-39.

17 Hagemeijer F, Van Houwe E. Titrated energy cardioversion of patients on digitalis. Br Heart $\mathcal{F} 1975 ; 37: 1303-7$.

18 Smith TW, Butler VP, Haber E, et al. Treatment of life-threatening digitalis intoxication with digoxin-specific $\mathrm{Fab}$ antibody fragments. $N$ Engl f Med 1982;307:1357-62.

19 Dreifus LS, McKnight EH, Katz M, Likoff W. Digitalis intolerance. Geriatrics 1963;18:494-502. 